\title{
PPBio Australasia Long Term Ecological Research Sites - flora and fauna database
}

\author{
Jean-Marc Hero, Gregory Lollback, Naomi Edwards, Sarah Butler, Rochelle Steven, Jon \\ Shuker, Clay Simpkins \& Guy Castley
}

\begin{abstract}
PPBio (Program for Planned Biodiversity and Ecosystem Research) Australasia Long Term Ecological Research Sites (GIVD ID AU-AU-001) is a system for long-term ecological research (LTER) designed to answer integrated multidisciplinary research questions. PPBio was developed in Brazil with a broad aim of establishing a cost-effective and efficient network of standardized LTER plots to collect comparable information on biodiversity and ecosystem processes around the world. Infrastructure includes permanent plots that follow contour lines (survey lines with all measurements recorded on the horizontal plane) which facilitate orthorectification and validation of satellite imagery. Grids and modules consist of arrays of plots located one kilometre apart (or 500 metres at small sites). Each plot has a 250 metre midline that is permanently marked at $10 \mathrm{~m}$ intervals. Plot width varies to suit the taxon or abiotic variable being examined. Small and/or numerous taxa are surveyed in narrow plots (e.g. frogs, reptiles, herbs and grasses are within a $2 \mathrm{~m}$ strip on one side of the midline) while wide plots are used for larger or more dispersed organisms (e.g. large trees, birds or small mammals). Low density species (e.g. large mammals such as monkeys, koalas and kangaroos) and additional environmental variables are monitored using the series of grid trails that connect the plots, using standardized sampling methodologies. The first PPBio LTER site at Karawatha Forest Park in Brisbane City (Queensland, Australia) was established in 2007. A second site was established at Lake Broadwater in the Brigalow Belt in 2008. The establishment of a third grid in Chitwan National Park in Nepal was initiated in 2009. A fourth grid with 40 plots was established in Currawinya National Park (western Queensland, Australia) in 2010, and a fifth project establishing modules at Cooloola in the Great Sandy National Park commenced in 2010. To date, vegetation has been measured at four sites (with approximately 99 one hectare plots now completed). Repeat surveys will provide data on vegetation productivity through time. All woody stemmed trees and shrubs are individually tagged and identified within each plot. A hierarchical design was used to sample trees of different size classes in order to estimate tree density. The diameter at breast height (DBH) was measured at $130 \mathrm{~cm}$ unless disfigurement made this impossible. Large trees (DBH $\geq 30 \mathrm{~cm})$ were sampled to $20 \mathrm{~m}$ either side of the midline ( $40 \mathrm{~m} \times 250 \mathrm{~m} \approx 1$ ha). Trees with $\mathrm{DBH} \geq 10 \mathrm{~cm}$ were sampled within $10 \mathrm{~m}$ either side of the midline $(20 \mathrm{~m} \times 250$ $\mathrm{m} \approx 0.5 \mathrm{ha}$ ). All woody stems with $\mathrm{DBH} \geq 1 \mathrm{~cm}$ were sampled along a $4 \mathrm{~m}$ strip on the right hand side of the midline $(4 \mathrm{~m} \mathrm{x} 250 \mathrm{~m} \approx$ 0.1 ha). The location of each tree is recorded in relation to its distance along the transect and distance from the transect. All trees are given an individual identifying number which is tagged to the tree and recorded in the vegetation database.
\end{abstract}

Keywords: Australia; biodiversity; ecology; forest; LTER; Nepal; PPBio; vegetation.

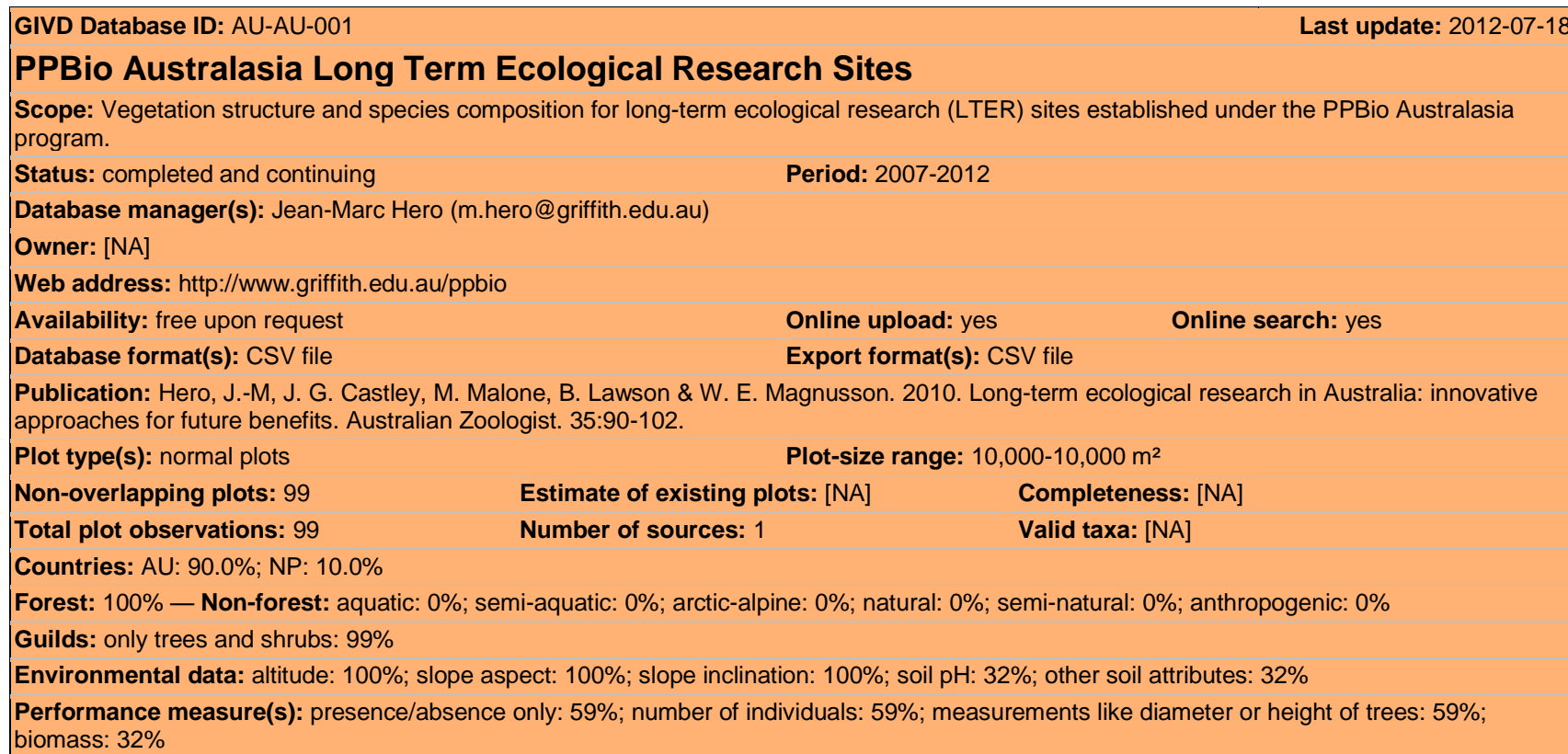


Geographic localisation: GPS coordinates (precision $25 \mathrm{~m}$ or less): $100 \%$

Sampling periods: 2000-2009: 60.0\%; 2010-2019: 40.0\%

Information as of 2012-07-25; further details and future updates available from http://www.givd.info/ID/AU-AU-001

Jean-Marc Hero* (m.hero@griffith.edu.au), Gregory Lollback (g.lollback@griffith.edu.au), Jon Shuker (j.shuker@griffith.edu.au), Clay Simpkins (c.simpkins@ griffith.edu.au)

Environmental Futures Centre, Griffith University, Parklands Drive, 4222 Gold Coast, AUSTRALIA

Naomi Edwards (n.edwards@griffith.edu.au), Sarah Butler (s.butler@griffith.edu.au), Rochelle Steven (r.steven@griffith.edu.au), Guy Castley (g.castley@griffith.edu.au)

School of Environment, Griffith University, Parklands Drive, 4222 Gold Coast, AUSTRALIA

*Corresponding author 